\title{
ARTICLE Sevoflurane promotes migration, invasion, and colony-forming ability of human glioblastoma cells possibly via increasing the expression of cell surface protein 44
}

\author{
Ren-chun Lai ${ }^{1,2}$, Wei-ran Shan ${ }^{1}$, Di Zhou ${ }^{1,3}$, Xiao-qing Zeng ${ }^{1}$, Kendrick Zuo ${ }^{1}$, Dong-feng Pan ${ }^{4}$, Wei-an Zeng ${ }^{2}$ and Zhi-yi Zuo ${ }^{1}$
}

\begin{abstract}
Surgical resection of primary solid tumor under anesthesia remains a common practice. It has been concerned whether general anesthetics, especially volatile anesthetics, may promote the growth, migration, and invasion of cancer cells. In this study, we examined the effects of sevoflurane on human glioblastoma cells and determined the role of cluster of differentiation (CD) 44 , a cell surface protein involved in cell growth, migration, and invasion, in sevoflurane's effects. We showed that exposure to $1 \%-4 \%$ sevoflurane did not change the cell proliferation, but concentration-dependently increased the invasion of human glioblastoma U251 cells. Furthermore, 4\% sevoflurane significantly increased the migration and colony-forming ability of U251 cells. Similar results were observed in human glioblastoma A172 cells. Exposure to sevoflurane concentration-dependently increased the activity of calpains, a group of cysteine proteinases, and CD44 protein in U251 and A172 cells. Knockdown of CD44 with siRNA abolished sevoflurane-induced increases in calpain activity, migration, invasion, and colony-forming ability of U251 cells. Inhalation of $4 \%$ sevoflurane significantly increased the tumor volume and invasion/migration distance of U87 cells from the tumor mass in the nude mice bearing human glioblastoma U87 xenograft in the brain. The aggravation by sevoflurane was attenuated by CD44 silencing. In conclusion, sevoflurane increases the migration, invasion, and colony-forming ability of human glioblastoma cells in vitro, and their tumor volume and invasion/migration in vivo. Sevoflurane enhances these cancer cell biology features via increasing the expression of CD44.
\end{abstract}

Keywords: sevoflurane; anesthetics; calpains; CD44; human glioblastoma; invasion; migration; colony forming

Acta Pharmacologica Sinica (2019) 40:1424-1435; https://doi.org/10.1038/s41401-019-0221-0

\section{INTRODUCTION}

Surgical resection of primary solid tumors under anesthesia remains a common practice. However, there has been concern that general anesthetics, especially volatile anesthetics, may enhance growth, migration, and invasion of cancer cells, which are biological processes necessary for cancer recurrence and metastasis [1]. For example, isoflurane has been shown to increase the migration of a human renal cancer cell line [2], although the opposite findings have been reported for volatile anesthetics in mouse colon cancer cells [3]. The effects of sevoflurane, the most commonly used volatile anesthetic in the U.S.A., on cells of human glioblastoma, a deadly human brain tumor, have not been reported.

Cancer cell migration and invasion are complex processes. It has been shown that matrix metalloproteinases (MMPs), especially MMP-2 and MMP-9, are involved in migration and invasion of cancer cells $[3,4]$. These MMPs can degrade components of the extracellular matrix to facilitate cell invasion. It has been shown that the effects of sevoflurane and desflurane, volatile anesthetics that are currently commonly used in clinical practice, on invasion of colorectal cancer cells are mediated by MMP-9 [3]. On the other hand, calpains, a family of calcium-dependent cysteine proteinases, have also been implicated in cancer cell migration and invasion $[5,6]$. Nevertheless, the role of calpains in the effects of anesthetics on cancer cells has not been reported.

Cluster of differentiation (CD) 44 is a cell surface protein that in its active form interacts with various proteins, including growth factor receptors, to activate intracellular signaling molecules, such as Akt, mitogen-activated protein kinase (MAPK), and calcium/ calmodulin-dependent protein kinase type II $[7,8]$. These protein kinases may then enhance the release of MMPs and calpains into the extracellular space to facilitate cell invasion [9-11]. The cytoplasmic tail of active CD44 can interact with members of the ezrin-radixin-moesin family or ankyrin to induce cytoskeletal changes that facilitate migration [8, 12]. Activation of Akt can enhance cell survival [8]. Thus, CD44 has a critical role in cancer malignancy behaviors. Interestingly, the role of CD44 in the effects of anesthetics on cancer cells is not known.

In this study, we determined the effects of sevoflurane on growth, migration, invasion, and colony-formation ability of

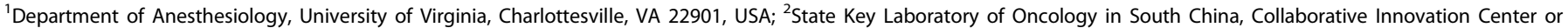

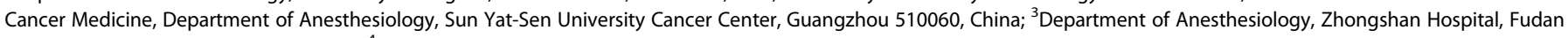
University, Shanghai 200032, China and ${ }^{4}$ Department of Radiology and Biomedical Imaging, University of Virginia, Charlottesville, VA 22908 , USA

Correspondence: Zhi-yi Zuo (zz3c@virginia.edu)

These authors contributed equally: Ren-chun Lai, Wei-ran Shan

Received: 21 November 2018 Accepted: 19 February 2019

Published online: 9 April 2019 
human glioblastoma cells. We hypothesized that CD44 has a critical role in the effects of sevoflurane on glioblastoma cells. To test this hypothesis, the expression of CD44 in these cells was measured and downregulated by RNA interference.

\section{MATERIALS AND METHODS}

The animal protocols were approved by the institutional Animal Care and Use Committee of the University of Virginia (Charlottesville, VA, USA; Protocol number: 4185). All animal and experimental procedures were carried out in accordance with the National Institutes of Health Guide for the Care and Use of Laboratory Animals (NIH publications number $80-23$ ) revised in 1996. Care was taken to limit the number of animals used and their suffering.

\section{Cell culture and randomization}

Three human glioblastoma cell lines, U251, A172, and U87, were used in this study because no one human cancer cell line can capture all the characteristics of the corresponding cancer [13], and using multiple cell lines in a study is a common practice [7, 14]. In this study, after examining the effects of sevoflurane on these three cell lines, U251 cells were used for mechanistic studies, and based on our previous experiments, U87 cells were used to develop xenografts in mouse brain because these cells can form xenografts in the brain [7], but U251 and A172 cells did not form xenografts in our hands.

U251 cells were maintained in Roswell Park Memorial Institute (RPMI)-1640 medium (Gibco, Grand Island, NY, USA) supplemented with $5 \%$ heat-inactivated fetal bovine serum (FBS) (Gibco). A172 cells were cultured in Dulbecco's modified Eagle's medium (DMEM) (American Type Culture Collection, Manassas, VA, USA) with $4.5 \mathrm{~g} / \mathrm{L}$ glucose and supplemented with $10 \%$ FBS. U87 cells were cultured in Minimum Essential Medium Eagle (MEM) (American Type Culture Collection, Manassas, VA, USA) supplemented with $1 \mathrm{mM}$ sodium pyruvate, $1 \%$ non-essential amino acids, $0.15 \%$ sodium bicarbonate, and $10 \%$ FBS. The cells were cultured as a monolayer at $37^{\circ} \mathrm{C}$ in humidified air balanced with $5 \%$ carbon dioxide. The culture medium was replaced every $48 \mathrm{~h}$. Cells used for trypan blue exclusion, cell migration, cell invasion, Western blotting, MMP-2/MMP-9 activity, and calpain activity assays were seeded at a density of $5 \times 10^{5}$ cells $/ \mathrm{mL}$ on six-well plates (Corning Life Science, Corning, NY, USA) and used experimentally when they were $90 \%$ confluent $24 \mathrm{~h}$ later. Cells used for 3-(4,5-dimethylthiazol-2-yl)-2,5-diphenyltetrazolium bromide (MTT) assays were plated at a density of $3 \times 10^{4}$ cells $/ \mathrm{mL}$ on 96-well plates.

The wells or whole plates of each set of cell cultures were randomly assigned to experimental conditions in each experiment. Microscopic fields used for cell counting were randomly selected during the Matrigel invasion assay. Randomization was not applied to any other experimental procedures. Blinding methods were used when counting the cells during the cell viability and Matrigel invasion assays.

\section{Sevoflurane gas exposure}

Cells were placed in modular incubator chambers (BillupsRothenberg Inc., San Diego, CA, USA) equipped with an inlet and outlet, which were used to provide continuous delivery of a gas mixture as we reported previously $[15,16]$. An in-line anesthetic vaporizer (Vaporizer Sale \& Service Inc., Rockmart, GA, USA) gassed with a gas mixture containing $21 \%$ oxygen and $5 \%$ carbon dioxide at a rate of $3 \mathrm{~L} / \mathrm{min}$ was used to deliver sevoflurane (Praxair Distribution Inc., Richmond, VA, USA) for at least $5 \mathrm{~min}$ until the desired sevoflurane concentration (1\%-4\%) was achieved. The concentration of sevoflurane in the sealed chamber was monitored at the chamber outlet port with an anesthetic analyzer (Datex-Engstrom, Helsinki, Finland). Once sealed, the chambers were placed in a $37^{\circ} \mathrm{C}$ incubator (NuAire Laboratory equipment, Plymouth, MN, USA) for $4 \mathrm{~h}$. This duration of sevoflurane exposure was chosen arbitrarily, but patients are often exposed to anesthetics for $4 \mathrm{~h}$ or longer during surgery to resect glioblastoma. The concentrations of sevoflurane were checked again at the end of incubation to preclude insufficient sealing of the chamber. Control cells were exposed to the air/5\% carbon dioxide mixture only. Cells were used for various assays 24 $\mathrm{h}$ after gas exposure. This duration of waiting was designed so that the proteins needed for the effects on migration, invasion, and colony formation could be expressed before those effects were assayed. In addition, these post-exposure effects are relevant to patients who undergo surgery for glioblastoma.

\section{Small interfering RNA for inhibition of CD44 expression} The CD44 small interfering RNA (siRNA) sequences were $5^{\prime}$ GAACGAAUCCUGAAGACAUCU-3' and 5'-AGAUGUCUUCAGGAUUC GUUC- $3^{\prime}$, and the negative control siRNA (non-targeting RNA) sequences were $5^{\prime}$-AAATGTACTGCGCGTGGAGAC-3' and 5'-GTCTC CACGCGCAGTACATTT-3'. These siRNAs were synthesized by Invitrogen (Carlsbad, CA, USA). For siRNA treatment, cells were plated in six-well plates at $5 \times 10^{5}$ cells per well $24 \mathrm{~h}$ before transfection. The cells were transfected with CD44 siRNA or nontargeting siRNA using Lipofectamine 2000 and Opti-Mem I (Invitrogen) following the manufacturer's protocol as we described previously $[17,18]$. The final siRNA concentration in a total of $2 \mathrm{~mL}$ of Opti-Mem I medium was $50 \mathrm{nM}$. The maximum reduction in CD44 expression occurred at $48 \mathrm{~h}$ post-transfection in U251 cells in our preliminary study. Thus, the cells were incubated with siRNA for $48 \mathrm{~h}$ and then used for transwell invasion, migration, and colony formation, calpain activity, and Western blotting assays of CD44.

Cell viability measurement

Cell viability was assessed using a trypan blue exclusion assay as preformed previously [19]. U251 cells were treated with different concentrations of sevoflurane $(0,1 \%, 2 \%, 3 \%$, or $4 \%)$ for $4 \mathrm{~h}$. Cells were removed from six-well plates by trypsinization $24 \mathrm{~h}$ later. Then, $100 \mu \mathrm{L}$ cell suspension was thoroughly mixed with $100 \mu \mathrm{L}$ trypan blue (Sigma, St. Louis, MO, USA) for 3 min. The mixture was placed on a hemocytometer. Under light microscopy, viable and non-viable cells in each of the four large hemocytometer squares were counted in a blinded fashion, and an average was calculated for further data analysis. Cell viability $(\%)=$ total viable cells (unstained)/total cells (stained and unstained) $\times 100 \%$.

\section{Cell proliferation measurement}

We used MTT assays to measure cell proliferation. U251 and U87 cells were seeded into a 96-well plate. Cells were exposed to different concentrations of sevoflurane $(0,1 \%, 2 \%, 3 \%$, or $4 \%)$ in the chamber and then cultured for $24 \mathrm{~h}$. MTT (catalog number: CT02; EMD Millipore, Billerica, MA, USA) solution was added into each well and incubated with cells for $4 \mathrm{~h}$ at $37^{\circ} \mathrm{C}$. Then, isopropanol with $0.04 \mathrm{M} \mathrm{HCl}$ was added to each well. Isopropanol dissolved the formazan to give a homogeneous blue solution that was suitable for absorbance measurement. The absorbance was measured at a test wavelength of $570 \mathrm{~nm}$ and a reference wavelength of $630 \mathrm{~nm}$ with a microplate reader (Model 680; BioRad Laboratories, Hercules, CA, USA). The OD of untreated cells was set to $100 \%$ to calculate the percentage of treated cell density using the following ratio $=O D_{\text {treated }} / O D_{\text {control }} \times 100 \%$.

Wound healing assay

U251, A172, or U87 cells were cultured in six-well plates and treated with $4 \%$ sevoflurane for $4 \mathrm{~h}$. Cell migration was measured using a wound healing assay $24 \mathrm{~h}$ after sevoflurane exposure. $\mathrm{A}$ 
straight scratch was made in each well with a $200 \mu \mathrm{L}$ pipette tip. The medium containing cell debris was aspirated away and replaced with fresh serum-free medium. The cells were then placed in a $5 \% \mathrm{CO}_{2}$ incubator. Wound healing was assessed at 0 and $24 \mathrm{~h}$ after the scratch using a light microscope at $\times 100$ magnification. The sizes and the lengths of the area without cells were measured using Image-Pro software (National Institutes of Health, Bethesda, MD, USA). The size of the area was divided by the length of the area to calculate the average distance that had not been covered by cells. The distance migrated at $24 \mathrm{~h}$ after wounding was then calculated.

Matrigel invasion assay

U251, A172, or U87 cells were cultured in six-well plates. Cells were treated with different concentrations of sevoflurane $(0,1 \%$, $2 \%, 3 \%$, or $4 \%$ ) for $4 \mathrm{~h}$. Twenty-four hours after exposure, cell invasion was assessed with a transwell invasion assay as described previously [7]. BD BioCoat Matrigel Invasion Chambers (24 wells, $8 \mu \mathrm{m}$ pore size; BD Biosciences, San Diego, CA, USA) were coated with collagen IV (BD Biosciences). Cells $\left(1 \times 10^{5}\right)$ were suspended in $300 \mu \mathrm{L} 0.1 \%$ FBS medium and added to the upper chamber of the wells. The lower chamber contained $600 \mu \mathrm{L} 10 \%$ FBS medium for U87 cells or 5\% FBS medium for U251 and A172 cells. The plate was kept in an incubator with $5 \%$ carbon dioxide for $8 \mathrm{~h}$ at $37^{\circ} \mathrm{C}$. Cells on the upper membrane surface were then mechanically removed. The cells that had migrated to the lower side of the collagen IV-coated membrane were fixed and stained with $0.1 \%$ crystal violet. Invasive cells were counted in five randomly chosen fields under a microscope at $\times 100$ magnification in a blind fashion, and the average number of these cells per field was calculated.

Colony-formation assay

U251 and A172 cells treated with or without 4\% sevoflurane for 4 $\mathrm{h}$ were cultured for another $24 \mathrm{~h}$ in fresh medium and then plated into 6-well plates at 100 cells per well density. Cells were cultured for 12 days to form colonies, with a medium change every 3 days. Cells were then fixed and stained with $1 \%$ crystal violet for $30 \mathrm{~min}$. Colonies with more than 50 cells were counted. The ratio (percentage) of the number of colonies to the number of cells seeded was calculated to reflect the colony-formation efficiency.

\section{Western blotting}

The expression of CD44 was analyzed via Western blotting. Cells were rinsed in ice-cold phosphate-buffered saline and lysed with RIPA buffer (Thermo Fisher Scientific, Waltham, MA, USA) containing a protease inhibitor cocktail (Sigma) and PhosSTOP phosphatase inhibitor cocktail (Roche, Mannheim, Germany). Cells were physically disrupted using a cell scraper. Ten micrograms of protein per lane were separated on a $10 \%$ gel (catalog number: 456-1035; Bio-Rad) and then transferred to a polyvinylidine difluoride membrane (catalog number: 162-0177; Bio-Rad). The membranes were blocked for $1 \mathrm{~h}$ in blocking buffer (Pierce Protein-free T20; catalog number: PI207535; Thermo Fisher Scientific). Primary mouse monoclonal anti-CD44 antibody (1:1000 dilution; catalog number: 8724S; Cell Signaling Technology, Danvers, MA, USA) and rabbit polyclonal anti-glyceraldehyde 3-phosphate dehydrogenase (GAPDH) antibody (1:5000 dilution; catalog number: G9545; Sigma) were applied, and the appropriate secondary antibodies were used. Protein bands were visualized using Genesnap version 7.08 and quantified with Genetools version 4.01 software. The relative protein expression of CD44 was normalized to the level of GAPDH expression in the same sample.

Measurement of MMP-2 and MMP-9 enzymatic activity U251 cells were cultured in 6-well plates. After being treated with different concentrations of sevoflurane for $4 \mathrm{~h}$, the cells were placed in a carbon dioxide incubator for an additional $24 \mathrm{~h}$. The activity of MMP-9 and MMP-2 in the culture medium was measured using zymography as performed previously [20]. Zymogram gels (Bio-Rad) containing gelatin as a substrate for MMP-9 and MMP-2 were used. The culture medium was mixed with non-reducing sample buffer containing $4 \%$ sodium dodecyl sulfate, $62.5 \mathrm{mM}$ Tris- $\mathrm{HCl}$ at $\mathrm{pH} 6.8,25 \%$ glycerol, and $0.01 \%$ bromophenol blue (catalog number: 161-0764; Bio-Rad). After electrophoresis, the gel was incubated in the renaturing buffer (catalog number: 161-0765; Bio-Rad) and then incubated overnight in the developing buffer (catalog number: 161-0766; BioRad). The gel was stained with 1\% Coomassie blue R250 (catalog number: 161-0400; Bio-Rad) for $1 \mathrm{~h}$. Gelatinolytic activity was observed as a clear band on the blue background of the Coomassie-stained gel. Gels were scanned using a Bio-Rad GS 800 densitometer. MMP-9 and MMP-2 activities were quantified by the raw volume of the band after the background intensity had been subtracted using ImageQuant TL 2005 software.

\section{Calpain-activity assay}

U251 cells were cultured in six-well plates $\left(5 \times 10^{5}\right.$ cells). After being treated with different concentrations of sevoflurane for 4 $\mathrm{h}$, the cells were placed in a carbon dioxide incubator for an additional $24 \mathrm{~h}$. Cells were resuspended in $100 \mu \mathrm{L}$ extraction buffer and homogenized by pipetting. Protein concentration was determined by the Bradford assay. Calpain activity was measured using a kit from Abcam (catalog number: ab65308; Abcam, Cambridge, MA, USA) according to the manufacturer's instructions. Calpain activity was analyzed using a fluorometer equipped with a 400-nm excitation filter and 505-nm emission filter.

Implantation of U87 cells into mouse brain and exposure to sevoflurane

U87 cells were incubated with or without CD44 siRNA or nontargeting RNA for $48 \mathrm{~h}$. The cells $\left(5 \mu \mathrm{L}\right.$ containing $\sim 1 \times 10^{5}$ cells) were injected into the posterior striatum of Hsd:Athymic NudeFoxn $1^{\text {nu }}$ mice (Envigo, Dublin, VA, USA) anesthetized with ketamine and xylazine. The coordinates for injection were $2.5 \mathrm{~mm}$ lateral to the middle line, $-1 \mathrm{~mm}$ from the bregma and a depth of $3 \mathrm{~mm}$ from the skull. The injection site was infiltrated with $2 \mathrm{mg} / \mathrm{kg}$ bupivacaine to relieve the pain. Animals injected with cells transfected with non-targeting RNA and CD44 siRNA were exposed to $4 \%$ sevoflurane (inhaled concentration) for $2 \mathrm{~h}$ on days 4 and 8 after injection. Their body temperature during anesthesia was maintained at $37^{\circ} \mathrm{C}$ with a water bath (Supplementary Figure 1). Four percent sevoflurane was used because one minimum alveolar concentration of sevoflurane in mice is $3.22 \%$ [21]. Four groups of animals were studied: control (8 mice), siRNA only (6 mice), non-targeting RNA plus sevoflurane (6 mice), and siRNA plus sevoflurane (9 mice).

Immunofluorescence staining and determination of tumor volumes and cell invasion in mouse brain

Two weeks after injection of U87 cells, mouse brains were harvested. Each whole brain was serially sectioned at a thickness of $10 \mu \mathrm{m}$. Ten sections at the injection site were used for immunofluorescence staining. Anti-human nucleus antibody clone 3E1.3 (1:200 dilution; catalog number: MAB4383, Millipore) was used for staining U87 cell nuclei. The secondary antibody was donkey anti-mouse IgG conjugated with Alexa Fluor 594 (1:200 dilution; catalog number: A-21203, Invitrogen). Sections were counterstained with Hoechst 33342 (1:1000 dilution; catalog number: 62249, Thermo Fisher Scientific, Pittsburgh, PA, USA) for 5 min, rinsed and mounted with Vectashield mounting medium (catalog number: $\mathrm{H}-1000$, Vector Laboratories, Burlingame, CA, USA). Images were acquired with a fluorescence microscope (Olympus DP70, Olympus Corporation, Tokyo, Japan). 
Tumor volumes were measured in a manner similar to that used previously to determine brain infarct volumes [20, 22]. The invasion distance of cells was assessed using a previously described method, with some modification [22]. These measurements were performed by a blinded observer using ImageJ software (National Institutes of Health, MD, USA). Tumor area was manually outlined with a freehand tool and then measured in $\mu \mathrm{m}^{2}$. The area was then multiplied by the section thickness $(10 \mu \mathrm{m})$ to obtain the tumor volume in the section. Volumes in all sections (10 s per mouse) were added together to obtain the total volume of each tumor. The invasion distance of cells from the edge of the main tumor bulk was measured using the straight tool in ImageJ. The invasion distances of all cells stained with antihuman nucleus antibody in 10 brain sections from each mouse were measured. The longest invasion distance of a U87 cell in each mouse was then identified. The total number of U87 cells that had migrated away from the tumor mass in each mouse was also determined.

Statistical analysis

Parametric results with a normal distribution are presented as the mean \pm S.D. $(n \geq 5)$. The sample size used in experiments was based on our previous experience [7]. Data were analyzed using one-way analysis of variance followed by Tukey's test if the data were normally distributed or using one-way analysis of variance on ranks followed by Tukey's test if the data were not normally distributed (the CD44 protein expression data and cell invasion data from experiments in which CD44 siRNA was used to attenuate sevoflurane effects were not normally distributed). Comparison of results from experiments with only two groups was performed using a $t$-test. Differences were considered significant at $P<0.05$ based on two-tailed hypothesis testing. All statistical analyses were performed with SigmaPlot 12.5 software (Systat Software, Inc., Point Richmond, (A, USA).

\section{RESULTS}

The data from every experiment are included and reported below. There are no missing experimental data.

Sevoflurane might not affect cell proliferation or induce glioblastoma cell death

Exposure to $1 \%-4 \%$ sevoflurane for $4 \mathrm{~h}$ did not significantly affect the results of MTT assays of U251 cells (Fig. 1a), suggesting that sevoflurane may not affect the proliferation of glioblastoma cells. In addition, the number of viable U251 cells according to trypan blue exclusion assays was not affected by sevoflurane exposure (Fig. 1b), suggesting that sevoflurane may not induce cell death. Consistent with the MTT and trypan blue assay results, the total number of U251 cells was not affected by sevoflurane exposure (Fig. 1c).

Sevoflurane enhanced invasion, migration, and colony-formation ability of glioblastoma cells

Sevoflurane dose-dependently increased the invasion ability of U251 cells. This effect was significant at a concentration as low as $1 \%$. The number of cells that invaded into the low chamber after exposure to $4 \%$ sevoflurane was more than three times that of the control cells (from $144 \pm 29$ cells per microscopic field to $450 \pm 176$ cells per microscopic field, $n=6, P<0.001$ ) (Fig. 2a, b). Consistent with the invasion results, $4 \%$ sevoflurane also increased the migration of U251 cells (Fig. 2c, d). Exposure to 4\% sevoflurane also increased the colony formation efficiency of U251 cells (from $17 \% \pm 9 \%$ to $24 \% \pm 8 \%, n=14, P=0.045$ ) (Fig. 2e, f). Similarly, $4 \%$ sevoflurane increased the migration, invasion, and colonyformation ability of $\mathrm{A} 172$ cells (Fig. 3 ).
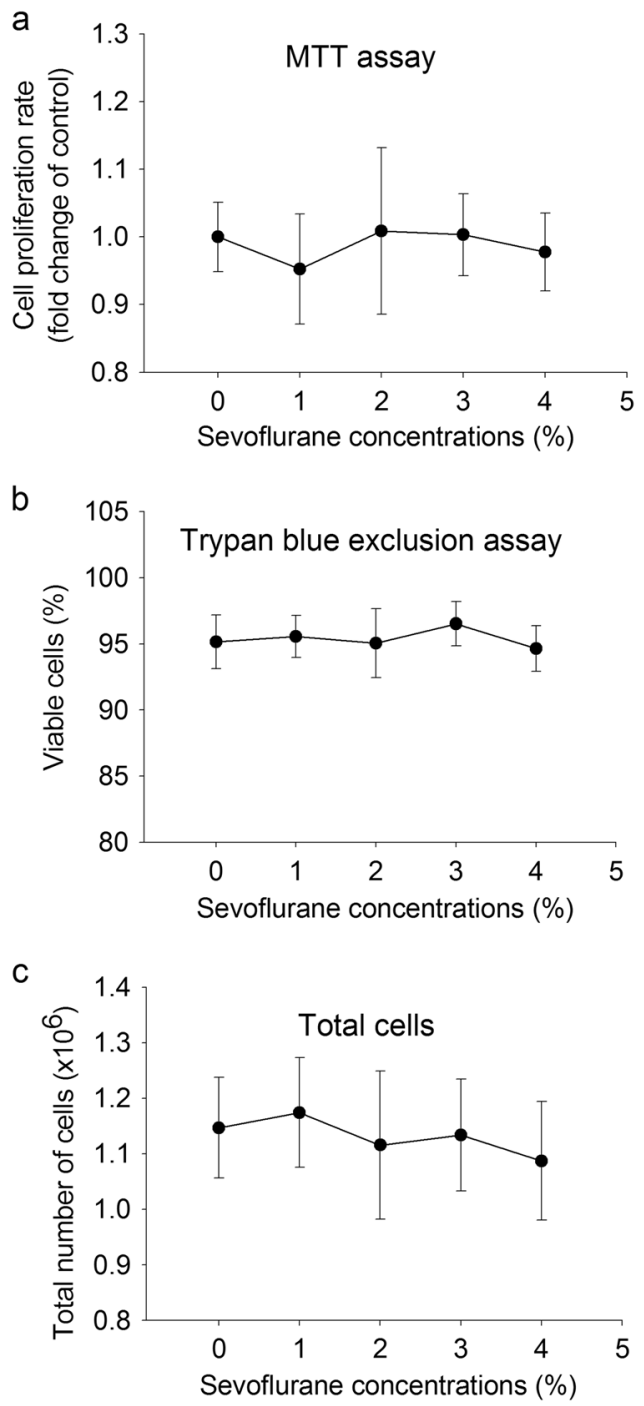

Fig. 1 No effect of sevoflurane on proliferation and cell death in U251 cells. U251 cells were exposed to various concentrations of sevoflurane for $4 \mathrm{~h}$. Cells were used for experiments $24 \mathrm{~h}$ later. a MTT results, $\mathbf{b}$ trypan blue exclusion results, and $\mathbf{c}$ total number of cells. The results are shown as the mean \pm S.D. ( $n=8$ for $\mathbf{a}$, and $n=12$ for b and $\mathbf{c}$ )

Sevoflurane increased calpain activity and CD44 expression Exposure to $1 \%$ to $4 \%$ sevoflurane did not affect MMP-2 and MMP9 activity in the culture medium of U251 cells (Fig. 4a-c). However, sevoflurane dose-dependently increased calpain activity. This effect reached significance at $3 \%$ and $4 \%$ sevoflurane (Fig. $4 d$ ). Sevoflurane also dose-dependently increased the expression of CD44 in U251 cells. This effect also reached significance at 3\% and $4 \%$ sevoflurane (Fig. 4e, f). Similarly, $4 \%$ sevoflurane increased CD44 expression in A172 cells (Fig. 3 ).

Reducing CD44 expression blocked the sevoflurane-induced increase in calpain activity and the malignant behavior of glioblastoma cells under in vitro conditions

As expected, siRNA against CD44 reduced CD44 expression while the transfection agent and non-targeting small RNA did not affect CD44 expression in U251 cells (Fig. 5a, b). siRNA against CD44 blocked the sevoflurane-induced increase in CD44 (Fig. 5c, d). In addition, the increase in calpain activity and invasion of U251 cells induced by 
a
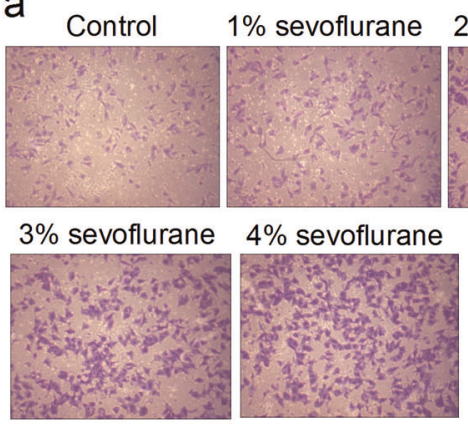

C

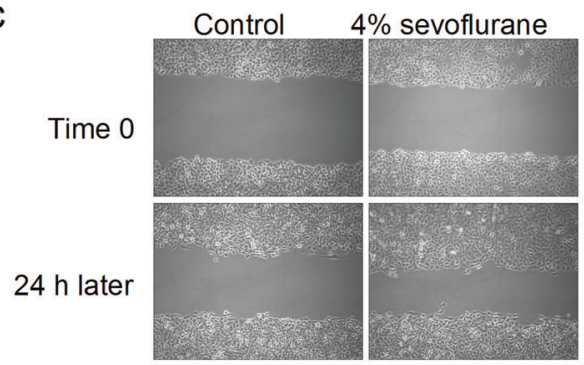

e



$2 \%$ sevoflurane
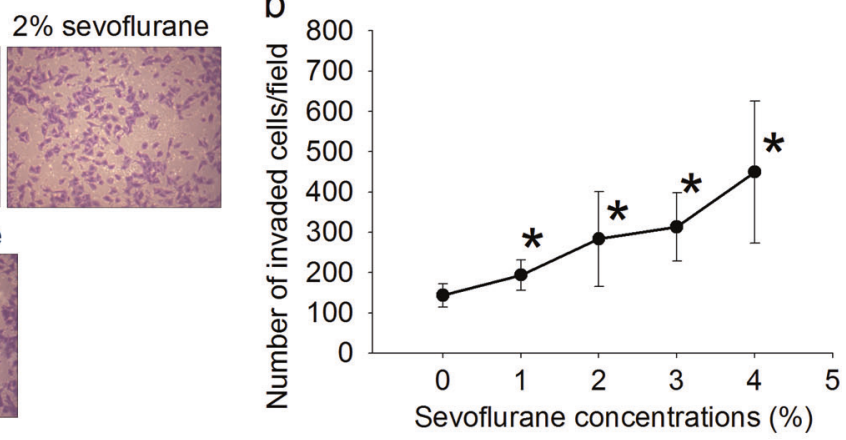

d



f

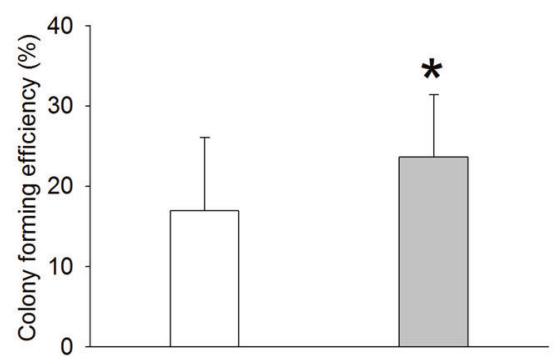

Fig. 2 Sevoflurane-induced increase in invasion, migration, and colony-formation in U251 cells. U251 cells were exposed to various concentrations of sevoflurane for $4 \mathrm{~h}$. Cells were used for experiments $24 \mathrm{~h}$ later. a Representative images of invaded cells, b quantitative results of cell invasion assay, $\mathbf{c}$ representative images of migration assay, $\mathbf{d}$ quantitative results of migration assay, e representative images of cell colonies, $\mathbf{f}$ quantitative results of colony-formation assay. The results are shown as the mean \pm S.D. $(n=6$ for $\mathbf{b}, n=17$ for $\mathbf{d}$ and $n=14$ for f). ${ }^{*} P<0.05$ compared with control

sevoflurane exposure was blocked by CD44 siRNA (Fig. 5e-g). CD44 siRNA also reduced the migration and colony formation ability of U251 cells stimulated by sevoflurane (Fig. 6a-d).

Reducing CD44 expression blocked the sevoflurane-induced malignant behavior of U87 cells under in vitro and in vivo conditions

Similar to the U251 cell results, sevoflurane did not affect the proliferation of U87 cell cultures as measured with MTT assays (Fig. 7a). However, 4\% sevoflurane increased CD44 expression and the migration and invasion ability of U87 cells under in vitro conditions (Fig. 7b-f). CD44 downregulation reduced the sevoflurane effects on the migration and invasion ability of U87 cells (Fig. 7c-f).

No mouse died during the in vivo cancer cell implantation experiment. Data from every mouse were included in the analysis. Sevoflurane increased the xenograft volumes and invasion/migration distance of U87 cells from the xenografts in the mouse brain (Fig. 8). These effects of sevoflurane on U87 cell xenografts were attenuated by CD44 siRNA (Fig. 8). Of note, the number of cells that migrated away from the tumor mass into brain tissues was not significantly different among the four experimental conditions studied (overall $P$ value was 0.108 , determined by one-way ANOVA), but the pattern of changes under these conditions appeared to be similar to that of tumor volumes and invasion (Fig. 8).

\section{DISCUSSION}

Human glioblastoma currently is an incurable brain tumor. Often, the edge of tumors is not clearly defined, and these tumors have a high recurrence rate after surgical resection [23]. Nevertheless, surgery is often performed to remove glioblastoma. Thus, the effects of general anesthetics on the cancer biology of these cells are clinically significant.

A significant finding of our study is that sevoflurane at clinically relevant concentrations increased invasion and migration of glioblastoma cells. This phenomenon occurred in all three cell lines tested in this study. It has been shown that serum from patients who underwent colon cancer surgery under sevoflurane anesthesia and were administered opioids increased the invasion of colon cancer cells in vitro compared with serum from patients whose colon surgery was conducted under propofol anesthesia with epidural analgesia. However, the study did not include a control group [24]. Thus, it is not known whether anesthesia and analgesia increase or decrease cell invasion compared with a control group. In another study, sevoflurane was found to increase invasion of estrogen receptor-positive breast cancer cells but did not affect the invasion of estrogen receptor-negative breast cancer cells [25]. A recent study showed that isoflurane increased migration of glioblastoma stem cells [22]. These previous studies are consistent with our finding that volatile anesthetics, such as 
a


e

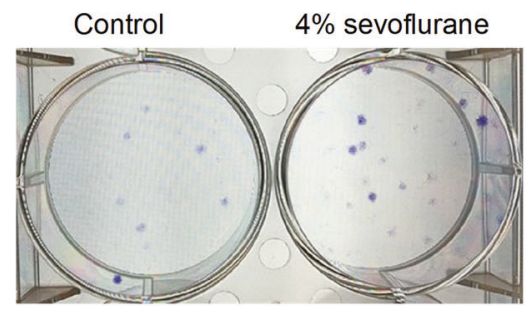

9



b

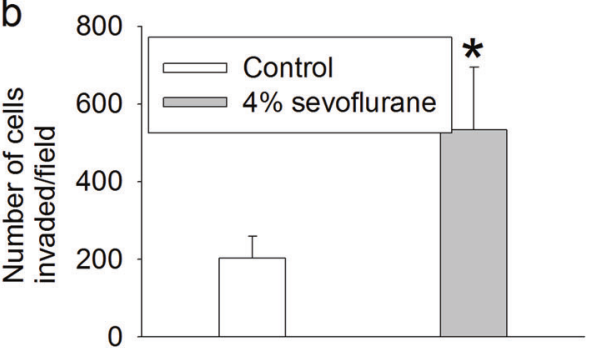

d

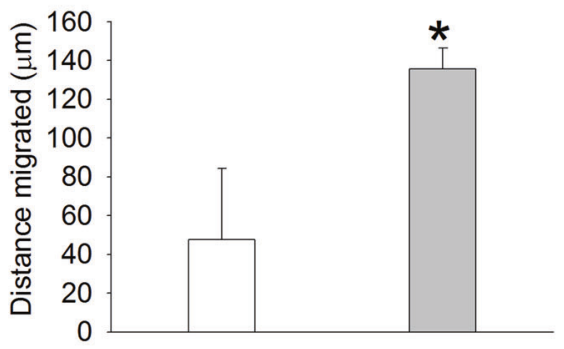

f

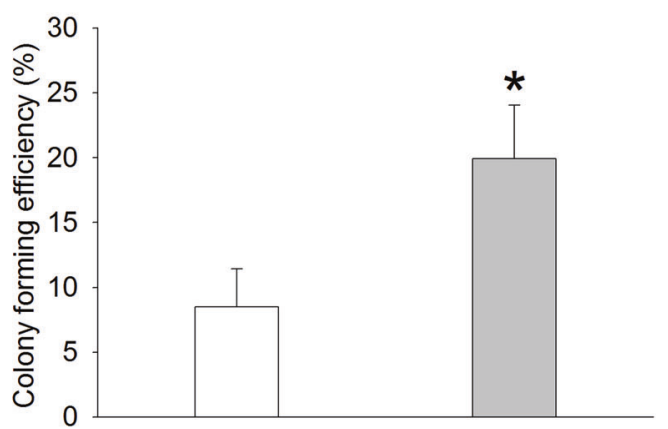

$\mathrm{h}$

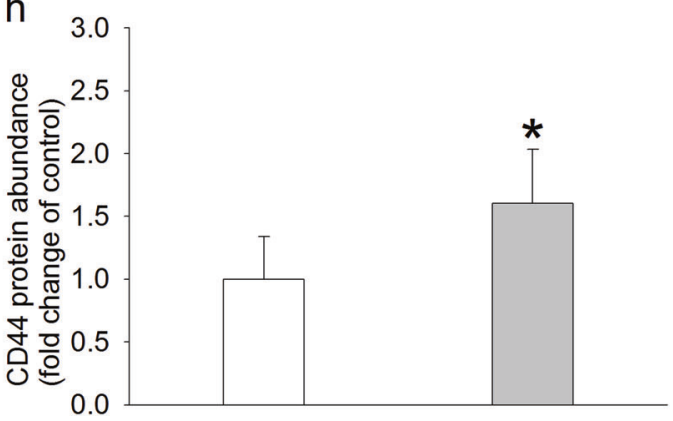

Fig. 3 Sevoflurane-induced increase in A172 cell invasion, migration, and colony formation. A172 cells were exposed to $4 \%$ sevoflurane for $4 \mathrm{~h}$. Cells were used for experiments $24 \mathrm{~h}$ later. a Representative images of invaded cells, b quantitative results of cell invasion assays, c representative images of migration assays, $\mathbf{d}$ quantitative results of migration assays, e representative images of cell colonies, $\mathbf{f}$ quantitative results of colony formation assays, $\mathbf{g}$ representative images of Western blotting analysis of CD44, with two representative results from control and $4 \%$ sevoflurane exposure conditions, and $\mathbf{h}$ quantitative results of CD44 expression analysis. The results are shown as the mean \pm S.D. ( $n=6$ for $\mathbf{b}, n=18$ for $\mathbf{d}, n=12$ for $\mathbf{f}$, and $n=6$ for $\mathbf{h}$ ). ${ }^{*} P<0.05$ compared with control

sevoflurane, enhance cancer cell invasion. However, sevoflurane and desflurane have been shown to reduce mouse colon cancer cell invasion [3]. Thus, the effects of volatile anesthetics on the invasion of cancer cells may vary among different cancer cells.

Interestingly, the above three papers showing that volatile anesthetics may increase the invasion of cancer cells did not include mechanistic studies. On the other hand, sevoflurane may inhibit MMP-9 to inhibit the invasion of mouse colon cancer cells [3]. MMP-2 and MMP-9 have been implicated in cancer cell invasion [3, 4]. These enzymes can degrade the extracellular matrix to facilitate migration and invasion of cancer cells.
However, our results showed that sevoflurane increased invasion of glioblastoma cells but did not affect MMP-2 and MMP-9 activities, suggesting that MMP-2 and MMP-9 may not be involved in this sevoflurane effect. Interestingly, sevoflurane dosedependently increased the activity of calpains. Calpains have been shown to facilitate the turnover of invadopodia [5], a structure used for invasion, and therefore can increase the invasion of cancer cells. Thus, calpains may be involved in the sevoflurane-induced increase in glioblastoma cell invasion.

Of note, sevoflurane increased CD44 expression in all three glioblastoma cell lines used in this study. CD44 is a key protein 
a

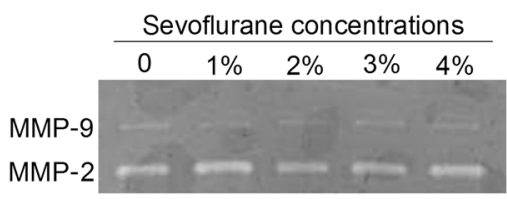

C

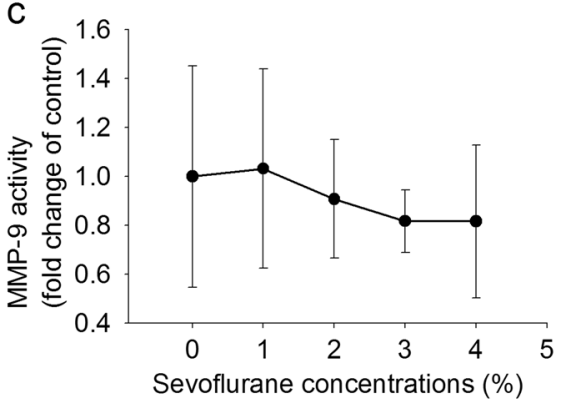

b
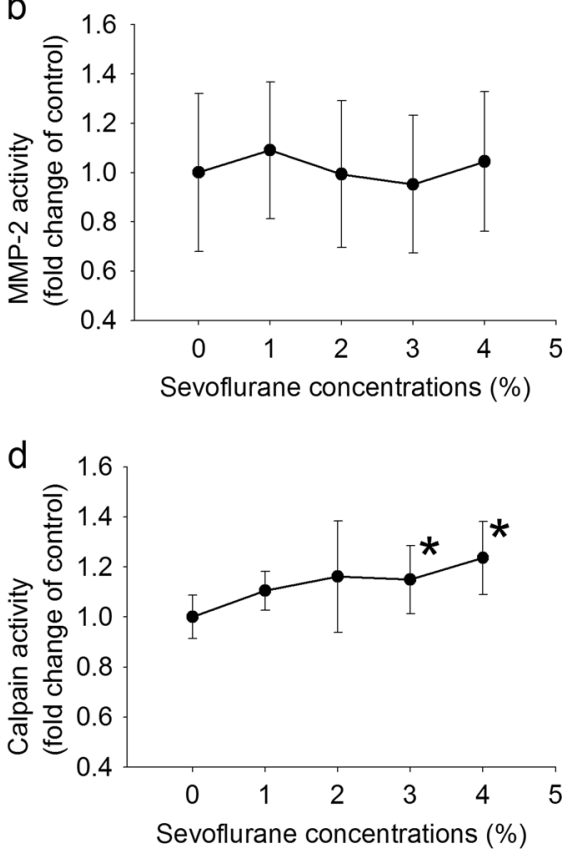

e
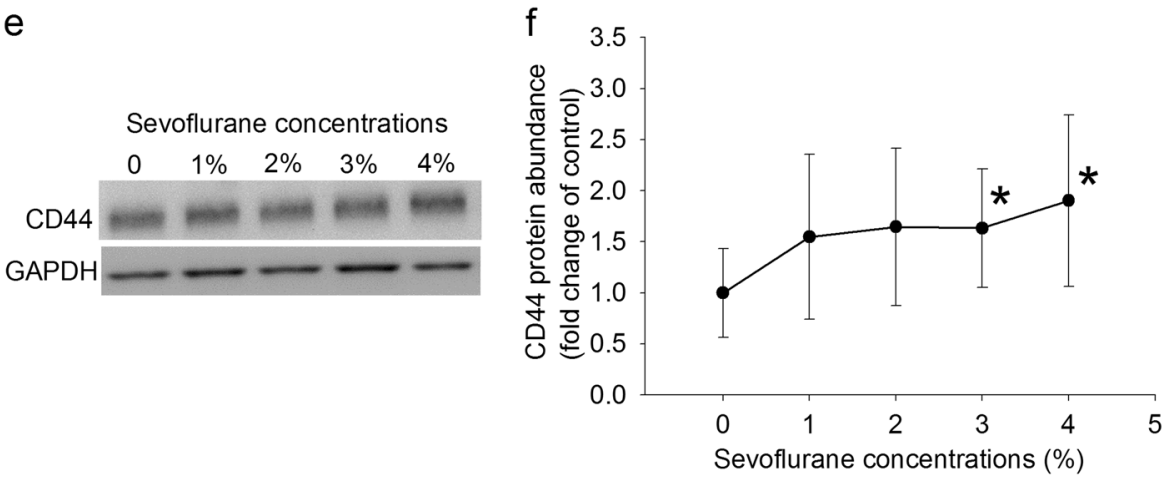

Fig. 4 Sevoflurane-induced increase in calpain activity and CD44 protein expression in U251 cells. U251 cells were exposed to various concentrations of sevoflurane for $4 \mathrm{~h}$. Cells were used for experiments $24 \mathrm{~h}$ later. a Representative zymogram images of MMP-2 and MMP-9, b quantitative assessment of MMP-2 activity, c quantitative assessment of MMP-9 activity, d quantitative assessment of calpain activity, e representative images of Western blotting analysis of CD44, and $\mathbf{f}$ quantitative assessment of CD44 expression. The results are shown as the mean \pm S.D. ( $n=8$ for $\mathbf{b}$ and $\mathbf{c}, n=6$ for $\mathbf{d}$, and $n=7$ for $\mathbf{f}$ ). ${ }^{*} P<0.05$ compared with control

that affects various cancer cell biology features by regulating intracellular signaling molecules [7, 8]. For example, CD44 can enhance Akt activity to increase cell growth $[7,26]$. CD44 can also activate MAPK to increase calpain activity $[9,10]$. Our previous study showed that CD44 can lead to MAPK activation in glioblastoma cells [7]. Here, we showed that sevoflurane increased CD44 in glioblastoma cells. CD44 silencing reduced calpain activity and malignant cell behavior, including migration, invasion, and colony formation, of glioblastoma cells in vitro and tumor growth and invasion/migration in vivo. These results suggest that CD44 is involved in the sevoflurane-induced increase in malignant behavior of glioblastoma cells. These results also provide additional evidence for the role of calpains in this increased invasion.

Of note, sevoflurane did not affect the results of MTT assays, total cell numbers or the number of viable U251 cells in our study. These results suggest that sevoflurane may not affect the proliferation and death of glioblastoma U251 cells. Sevoflurane has been shown to increase the proliferation of breast cancer cells [25]. However, it was also reported that sevoflurane inhibits the growth of lung cancer cells induced by hypoxia [27]. Our study showed that sevoflurane did not affect MTT assay results in U87 cell cultures but increased the tumor volumes of these cells in the brain. These results may suggest that sevoflurane does not affect the proliferation of these cells but inhibits their death to increase tumor volumes. It is also possible that sevoflurane induces cell proliferation under in vivo conditions but not under in vitro conditions because the complex environment in the brain does not exist in cell culture. Since CD44 silencing inhibited tumor volume increase, this sevoflurane effect may also be mediated by CD44. CD44 can increase Akt and MAPK activities, which are beneficial for cell survival and proliferation [7, 26]. Consistent with this possibility, sevoflurane increased CD44 and colony formation, and downregulating CD44 reduced colony formation.

Our results also showed that sevoflurane increased the migration and invasion of glioblastoma cells under in vitro conditions. These effects were confirmed in mouse brain. Invadopodia are F-actin-rich membrane protrusions from which enzymes, such as MMPs, can be secreted [28]. These protrusions are critical structures for invasion [29]. On the other hand, integrin- 
a

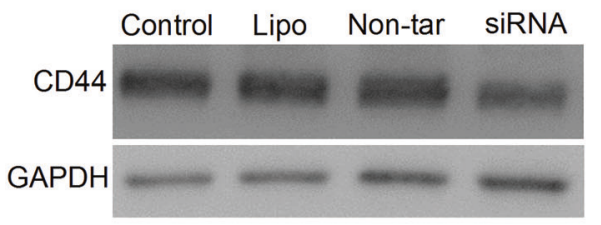

C

Sevo+ Sevo+

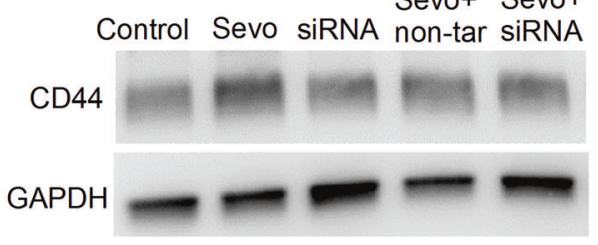

f

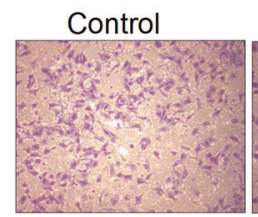

SiRNA
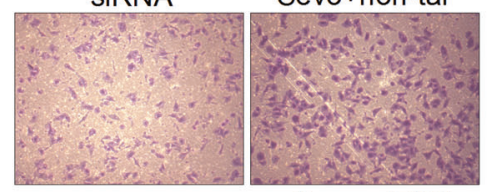

Sevo+siRNA

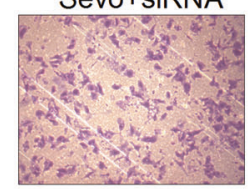

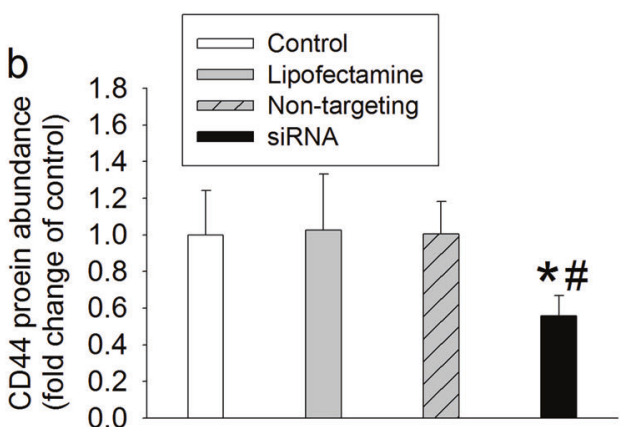

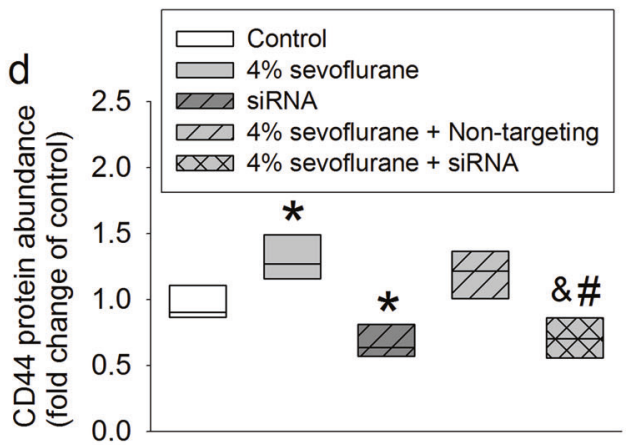

e
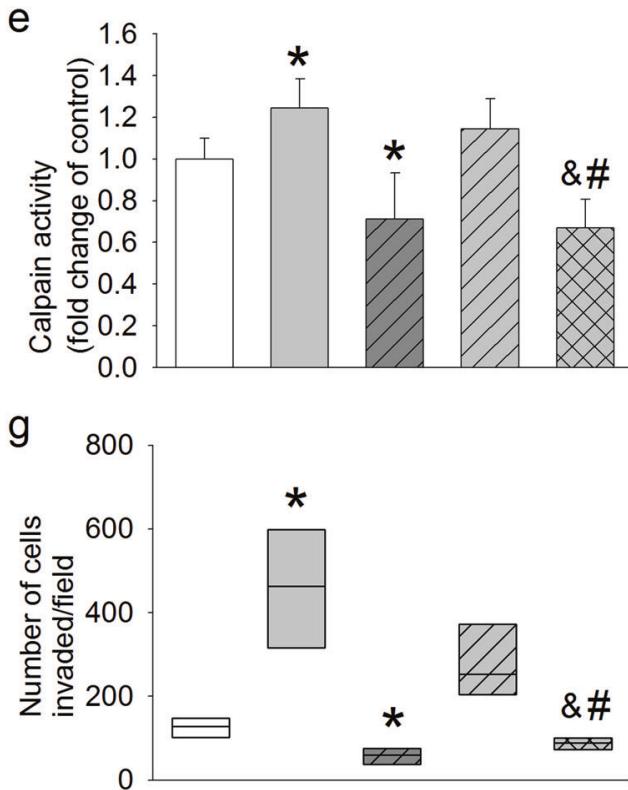

Fig. 5 Blocking of the sevoflurane-induced increase in calpain activity and invasion of U251 cells via CD44 downregulation. U251 cells were transfected with CD44 siRNA or non-targeting siRNA for $48 \mathrm{~h}$ and harvested for analysis to generate the results shown in a and $\mathbf{b}$ or exposed to $4 \%$ sevoflurane for $4 \mathrm{~h}$ and then used in experiments to generate the results shown in $\mathbf{c}-\mathbf{g}$. a Representative Western blotting images of CD44 expression in cells without sevoflurane exposure, b quantitative results of CD44 expression in cells without sevoflurane exposure, c representative images of Western blotting of CD44 in cells exposed to sevoflurane, $\mathbf{d}$ quantitative results of CD44 expression in cells exposed to sevoflurane, e quantitative assessment of calpain activity, $\mathbf{f}$ representative images of invaded cells, $\mathbf{g}$ quantitative results of invasion assays. The results are shown as the mean \pm S.D. $(\mathbf{b}, \mathbf{e})$ or in a box plot in which the box represents the $25 \%$ to $75 \%$ interval and the median of the data is shown as a line inside the box $(\mathbf{d}, \mathbf{g})(n=6) .{ }^{*} P<0.05$ compared with control. ${ }^{\&} P<0.05$ compared with sevoflurane alone. ${ }^{\#} P<0.05$ compared with sevoflurane plus non-targeting siRNA. Sevo: $4 \%$ sevoflurane, non-tar: non-targeting RNA

based focal adhesions are structures utilized for migration. Focal adhesions are attached to the extracellular matrix and activate cytoskeletal reorganization to generate traction forces for migration [30]. Invadopodia and focal adhesions are distinct and highly dynamic structures that facilitate invasion and migration, respectively [30], and both can be regulated by MAPK [30, 31]. Isoflurane has been shown to enhance migration and cytoskeletal reorganization in human renal cancer cells [2]. Our results suggest that sevoflurane has similar effects on glioblastoma cells.

Migration and invasion are basic biological processes necessary for tumor cells to metastasize. Sevoflurane increased the migration and invasion of human glioblastoma cells. Metastasis requires formation of a colony in another location. Our results also showed that sevoflurane increased the colony formation efficiency 


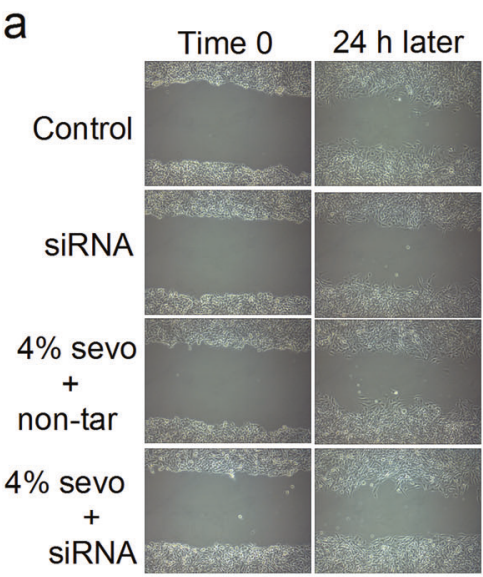

C

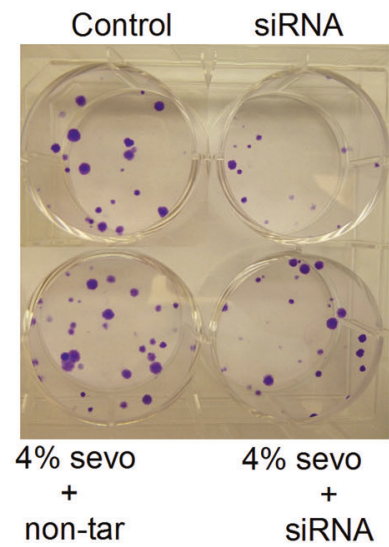

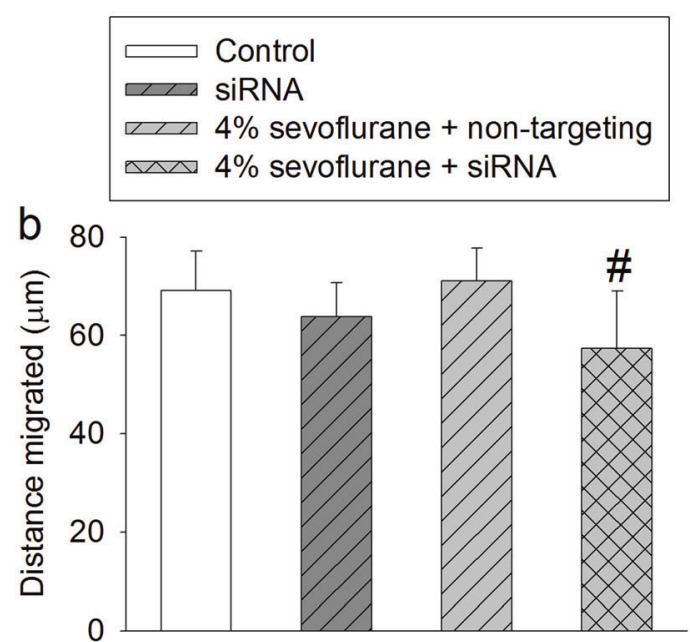

$\mathrm{d}$

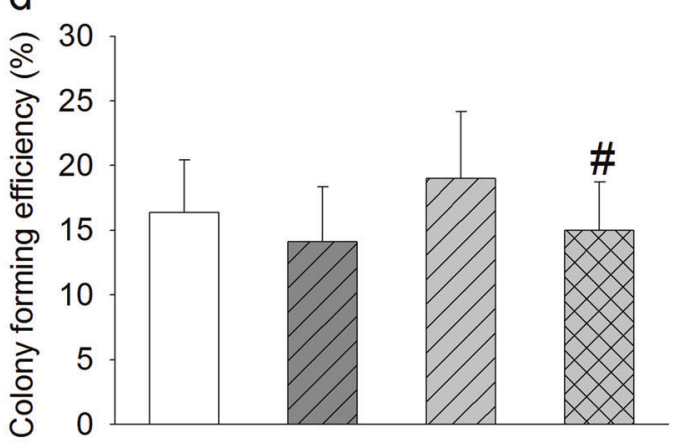

Fig. 6 Blocking of the sevoflurane-induced increase in migration and colony formation of U251 cells via CD44 downregulation. U251 cells were transfected with CD44 siRNA or non-targeting siRNA for $48 \mathrm{~h}$, exposed to $4 \%$ sevoflurane for $4 \mathrm{~h}$ and then used in experiments to generate the results shown in a-d. a Representative images of migration assays, $\mathbf{b}$ quantitative results of migration assays, $\mathbf{c}$ representative images of cell colonies, $\mathbf{d}$ quantitative results of colony-formation assays. The results are shown as the mean \pm S.D. $(n=9-42)$. ${ }^{\sharp} P<0.05$ compared with sevoflurane plus non-targeting siRNA. Sevo: sevoflurane, non-tar: non-targeting RNA

of U251 and A172 cells. Colony formation assays have been used to determine cell survival [32]. Our results suggest that sevoflurane facilitates survival and colony formation of human glioblastoma cells in the local environment. Halothane was found to have no effect on colony formation of lymphoma cells [33]. Our results provide initial evidence that anesthetics, such as sevoflurane, may enhance metastasis of glioblastoma cells. Of note, our study showed that sevoflurane increased colony formation of U251 cells but did not appear to affect their proliferation, assessed by MTT assays. These findings are understandable because colony formation reflects cell survival and proliferation when only a few cells are initially present or even single cell, while the MTT assay measures proliferation of a large number of cells.

We performed a dose-response study to examine sevoflurane effects on invasion; the activity of MMP-2, MMP-9 and calpains; and CD44 protein expression in U251 cells but used $4 \%$ sevoflurane in other studies. This concentration should be clinically relevant because the brain/blood partition coefficient is 1.7 for sevoflurane [34]. The blood/gas partition coefficient for sevoflurane is 0.74 [35], but the electrolyte solution (similar to our culture medium)/gas partition coefficient for sevoflurane is 0.31 [36]. Thus, the sevoflurane concentration in the culture medium surrounding our cell cultures when $4 \%$ sevoflurane in gas was applied should be within the sevoflurane concentration range in the brain during clinical anesthesia because the concentration of sevoflurane in the brain could be four times that in culture medium when the same concentration of sevoflurane in the gas phase are applied $(1.7 \times 0.74 / 0.31=4.05)$.

A significant strength of our study is the use of multiple human glioblastoma cell lines to show the effects of sevoflurane on cancer cell biology behavior. Detailed characterization of these effects, such as dose-response studies, and mechanistic investigation were performed in U251 cells, the first cell line used in this study. To determine whether the in vitro findings are applicable in the brain, the organ in which glioblastoma occurs, we implanted U87 cells into mouse brains. Together, our results suggest that the sevoflurane-enhanced cancer cell biology behaviors are not specific to one human glioblastoma cell line and that the in vitro findings are applicable in the mouse brain.

Clinically, the effects of volatile anesthetics on patient outcome after surgery for cancer are not clear. A recent retrospective study showed that patients that underwent surgery for cancer under volatile anesthetics had a lower long-term survival rate than patients anesthetized with intravenous anesthetics [37]. These results are consistent with previous findings that intravenous agents, such as lidocaine and propofol, can inhibit the proliferation, migration, and invasion of cancer cells under in vitro conditions [11, 38]. However, a previous retrospective study did not show significant benefits of propofol anesthesia over sevoflurane anesthesia in patients undergoing surgery for cancer [39]. Prospective randomized clinical studies are needed to 

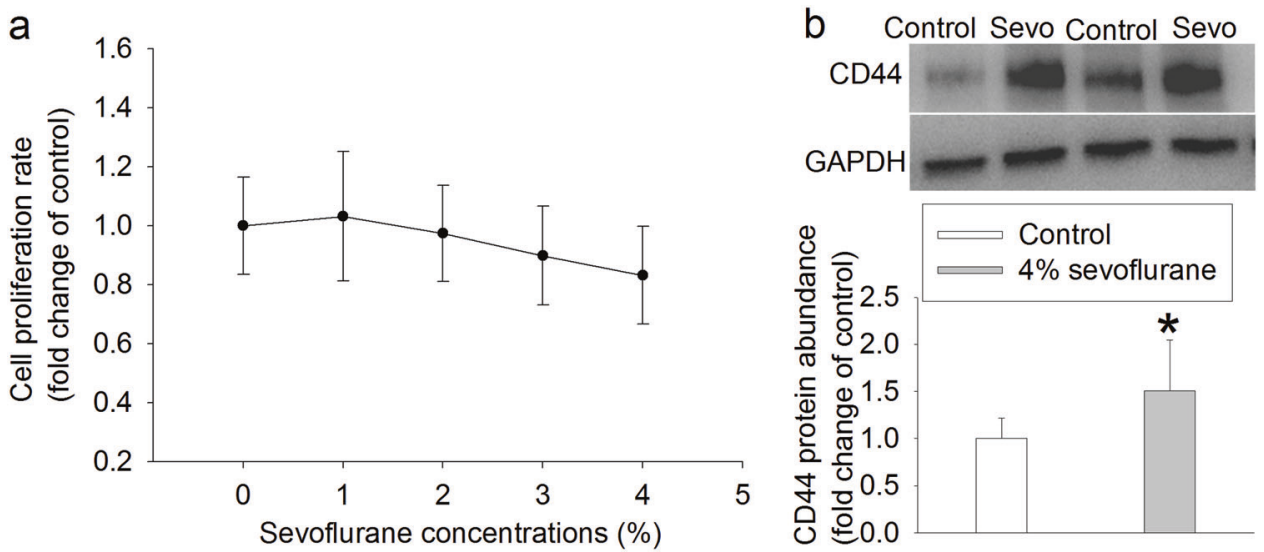

C
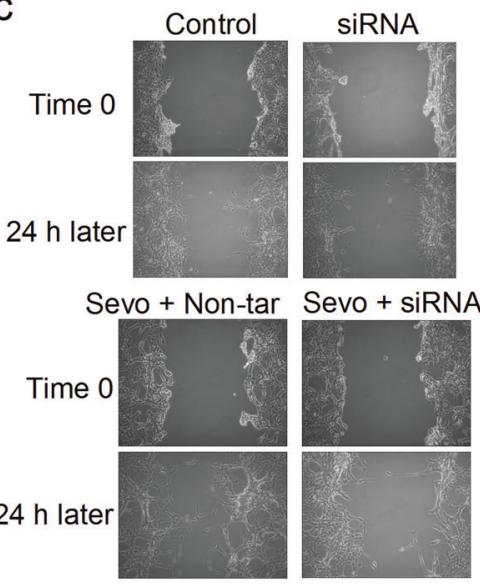

e



$\mathrm{d}$
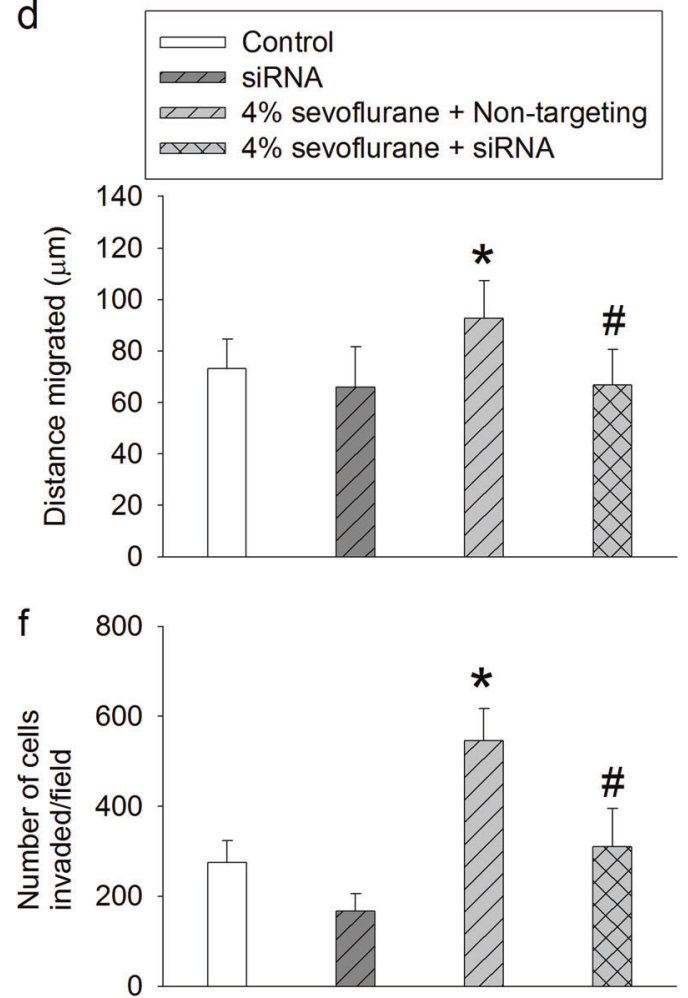

Fig. 7 Role of CD44 in sevoflurane-induced increase in U87 cell migration and invasion. U87 cells were exposed to various concentrations of sevoflurane for $4 \mathrm{~h}$. Cells were used for MTT assays $24 \mathrm{~h}$ later to generate the results shown in a. U87 cells were exposed to $4 \%$ sevoflurane for $4 \mathrm{~h}$ and used $24 \mathrm{~h}$ later for Western blotting to generate the results shown in b. In another experiment, U87 cells were transfected with CD44 siRNA or non-targeting siRNA for $48 \mathrm{~h}$, exposed to $4 \%$ sevoflurane for $4 \mathrm{~h}$ and then used in experiments to generate the results shown in c-f. a MTT results, b CD44 expression (top panel: representative Western blotting images of CD44 expression, with two representative blots from control and $4 \%$ sevoflurane exposure conditions; bottom panel: quantitative assessment of CD44 expression), c representative images of migration assays, $\mathbf{d}$ quantitative results of migration assays, e representative images of invaded cells, $\mathbf{f}$ quantitative results of invasion assays. The results are shown as the mean \pm S.D. $(n=17-32)$. ${ }^{*} P<0.05$ compared with control. ${ }^{\#} P<0.05$ compared with sevoflurane plus nontargeting siRNA. Sevo: $4 \%$ sevoflurane, non-tar: non-targeting RNA

determine whether anesthetic choice is important for cancer recurrence and survival benefit.

Our study has limitations. We have shown a critical role of CD44 in the effects of sevoflurane on cancer cell behavior under in vitro and in vivo conditions, a novel mechanism by which volatile anesthetics can affect cancer cells. However, we have not defined the intracellular signaling molecules downstream of CD44 involved in the effects of sevoflurane. Nevertheless, many intracellular signaling molecules have been identified that are necessary for CD44 to regulate cell proliferation, migration, and invasion [7-12, 31]. These well-defined signaling molecules downstream of CD44, such as MAPK and Akt, may mediate the effects of sevoflurane on cancer cell behaviors. Another limitation of our study is that the mechanism by which sevoflurane increases CD44 expression was not determined. This determination will be performed in our future studies.

In summary, our study showed that sevoflurane enhances cancer cell biology behaviors, including migration, invasion, and the colony formation ability of glioblastoma cells. These effects may be mediated by increased CD44 expression. Together, these results suggest that sevoflurane may facilitate metastasis of human glioblastoma cells. 




$4 \%$ sevo + Non-targeting $4 \%$ sevo + siRNA

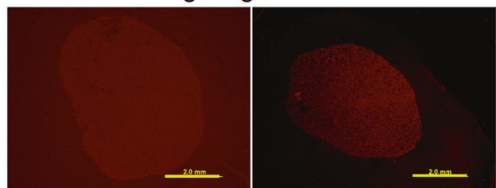

C
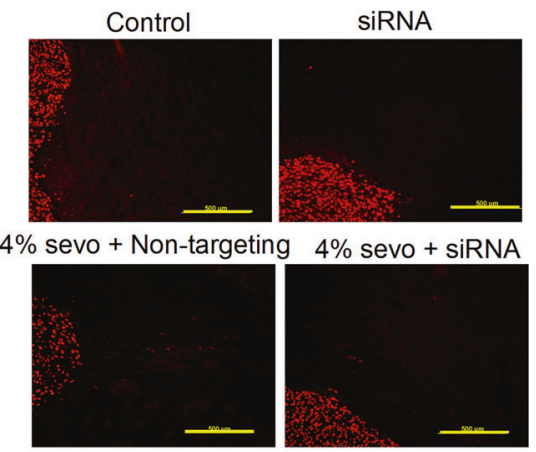

e

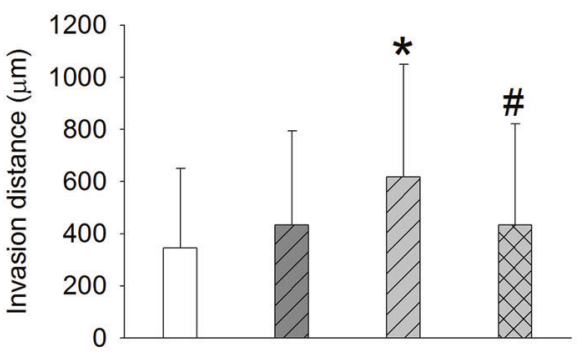

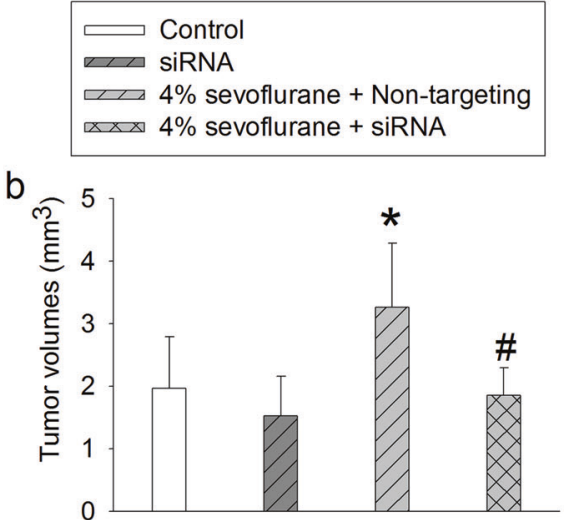

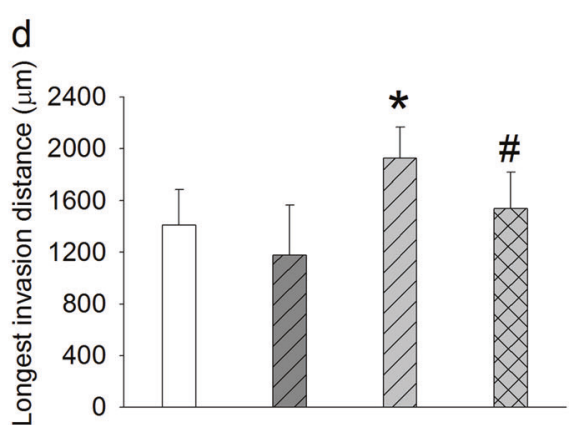

f

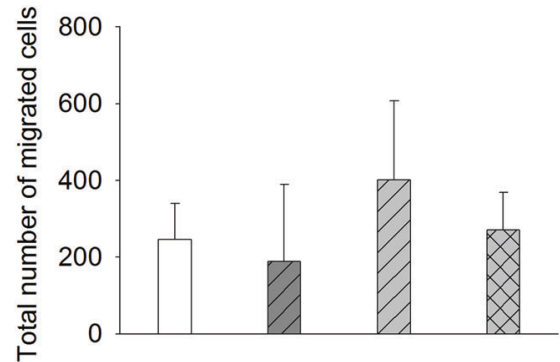

Fig. 8 Role of CD44 in xenograft growth and cell invasion in mouse brains. U87 cells were transfected with CD44 siRNA or non-targeting siRNA for $48 \mathrm{~h}$ and then implanted into mouse striatum. Mice were then exposed to sevoflurane on days 4 and 8 for $2 \mathrm{~h}$ and brains were harvested on day 14 after siRNA injection. a Representative images of brain sections after immunofluorescence staining to show tumor mass (scale bar $=2 \mathrm{~mm}$ ), $\mathbf{b}$ tumor volumes, $\mathbf{c}$ representative images of brain sections after immunofluorescence staining to show cell invasion (scale $\mathrm{bar}=0.5 \mathrm{~mm}$ ), $\mathbf{d}$ longest invasion distance of cells in each mouse, $\mathbf{e}$ invasion distances of all visible U87 cells in mice, $\mathbf{f}$ number of all visible U87 cells outside of the main mass in each mouse. The results are shown as the mean \pm S.D. $(n=6-9$ for $\mathbf{b}$, $\mathbf{d}$, and $\mathbf{f}$, and $n=1124-2410$ cells for e). ${ }^{*} P<0.05$ compared with control. ${ }^{\#} P<0.05$ compared with sevoflurane plus non-targeting siRNA. Sevo: $4 \%$ sevoflurane, non-targeting: non-targeting RNA

\section{ACKNOWLEDGEMENTS}

This study was supported by grants (GM098308 and AG047472 to ZYZ) from the National Institutes of Health, Bethesda, MD, and the Robert M. Epstein Professorship endowment, University of Virginia, Charlottesville, VA, USA.

\section{AUTHOR CONTRIBUTIONS}

ZYZ conceived the project. RCL, WRS, DZ, DFP, WAZ, and ZYZ designed the study; $\mathrm{RCL}, \mathrm{WRS}, \mathrm{DZ}, \mathrm{XQZ}$, and $K Z$ performed the experiments. $R C L, W R S$, and $D Z$ performed the initial data analysis. RCL and WRS drafted the Methods section. ZYZ performed the final data analysis and wrote the manuscript.

\section{ADDITIONAL INFORMATION}

The online version of this article (https://doi.org/10.1038/s41401-019-0221-0) contains supplementary material, which is available to authorized users.

Competing interests: The authors declare no competing interests.

\section{REFERENCES}

1. Heaney A, Buggy DJ. Can anaesthetic and analgesic techniques affect cancer recurrence or metastasis? Br J Anaesth. 2012;109(Suppl 1):i17-i28.

2. Benzonana LL, Perry NJ, Watts HR, Yang B, Perry IA, Coombes $C$, et al. Isoflurane, a commonly used volatile anesthetic, enhances renal cancer growth and malignant potential via the hypoxia-inducible factor cellular signaling pathway in vitro. Anesthesiology. 2013;119:593-605.

3. Muller-Edenborn B, Roth-Z'graggen B, Bartnicka K, Borgeat A, Hoos A, Borsig L, et al. Volatile anesthetics reduce invasion of colorectal cancer cells through down-regulation of matrix metalloproteinase-9. Anesthesiology. 2012;117: 293-301.

4. Kalhori V, Tornquist K. MMP2 and MMP9 participate in S1P-induced invasion of follicular ML-1 thyroid cancer cells. Mol Cell Endocrinol. 2015;404:113-22.

5. Hoskin V, Szeto A, Ghaffari A, Greer PA, Cote GP, Elliott BE. Ezrin regulates focal adhesion and invadopodia dynamics by altering calpain activity to promote breast cancer cell invasion. Mol Biol Cell. 2015;26:3464-79.

6. Chen B, Tang J, Guo YS, Li Y, Chen ZN, Jiang JL. Calpains are required for invasive and metastatic potentials of human HCC cells. Cell Biol Int. 2013;37:643-52. 
7. Feng C, Zhang Y, Yin J, Li J, Abounader R, Zuo Z. Regulatory factor X1 is a new tumor suppressive transcription factor that acts via direct downregulation of CD44 in glioblastoma. Neuro Oncol. 2014;16:1078-85.

8. Toole BP. Hyaluronan-CD44 interactions in cancer: paradoxes and possibilities. Clin Cancer Res. 2009;15:7462-8.

9. Leloup L, Daury L, Mazeres G, Cottin P, Brustis JJ. Involvement of the ERK/MAP kinase signalling pathway in milli-calpain activation and myogenic cell migration. Int J Biochem Cell Biol. 2007;39:1177-89.

10. Glading A, Uberall F, Keyse SM, Lauffenburger DA, Wells A. Membrane proximal ERK signaling is required for $M$-calpain activation downstream of epidermal growth factor receptor signaling. J Biol Chem. 2001;276:23341-8.

11. Xu YB, Du QH, Zhang MY, Yun $P$, He CY. Propofol suppresses proliferation invasion and angiogenesis by down-regulating ERK-VEGF/MMP-9 signaling in Eca-109 esophageal squamous cell carcinoma cells. Eur Rev Med Pharmacol Sci. 2013;17:2486-94.

12. Ponta $H$, Sherman L, Herrlich PA. CD44: from adhesion molecules to signalling regulators. Nat Rev Mol Cell Biol. 2003:4:33-45.

13. Gillet JP, Varma S, Gottesman MM. The clinical relevance of cancer cell lines. J Natl Cancer Inst. 2013;105:452-8.

14. Kim J, Zhang Y, Skalski M, Hayes J, Kefas B, Schiff D, et al. microRNA-148a is a prognostic oncomiR that targets MIG6 and BIM to regulate EGFR and apoptosis in glioblastoma. Cancer Res. 2014;74:1541-53.

15. Lin D, Feng C, Cao M, Zuo Z. Volatile anesthetics may not induce significan toxicity to human neuron-like cells. Anesth Analg. 2011;112:1194-8.

16. Zuo Z, Johns RA. Inhalational anesthetics up-regulate constitutive and lipopolysaccharide-induced inducible nitric oxide synthase expression and activity. Mol Pharmacol. 1997;52:606-12.

17. Ma K, Zheng S, Zuo Z. The transcription factor regulatory factor $X 1$ increases the expression of neuronal glutamate transporter type 3. J Biol Chem. 2006;281: 21250-5.

18. Feng $C$, Zuo Z. Regulatory factor $\mathrm{X} 1$-induced down-regulation of transforming growth factor beta2 transcription in human neuroblastoma cells. J Biol Chem. 2012;287:22730-9.

19. Xu X, Feng J, Zuo Z. Isoflurane preconditioning reduces the rat NR8383 macrophage injury induced by lipopolysaccharide and interferon gamma. Anesthesiology. 2008;108:643-50.

20. Deng J, Zhang J, Feng C, Xiong L, Zuo Z. Critical role of matrix metalloprotease- 9 in chronic high fat diet-induced cerebral vascular remodelling and increase of ischaemic brain injury in mice. Cardiovasc Res. 2014;103:473-84.

21. Ichinose F, Mi WD, Miyazaki M, Onouchi T, Goto T, Morita S. Lack of correlation between the reduction of sevoflurane MAC and the cerebellar cyclic GMP concentrations in mice treated with 7-nitroindazole. Anesthesiology. 1998;89:143-8.

22. Zhu M, Li M, Zhou Y, Dangelmajer S, Kahlert UD, Xie R, et al. Isoflurane enhances the malignant potential of glioblastoma stem cells by promoting their viability, mobility in vitro and migratory capacity in vivo. Br J Anaesth. 2016;116:870-7.
23. Giese A, Bjerkvig R, Berens ME, Westphal M. Cost of migration: invasion of malignant gliomas and implications for treatment. J Clin Oncol. 2003;21:1624-36.

24. Xu YJ, Li SY, Cheng Q, Chen WK, Wang SL, Ren Y, et al. Effects of anaesthesia on proliferation, invasion and apoptosis of LoVo colon cancer cells in vitro. Anaesthesia. 2016;71:147-54.

25. Ecimovic $P$, McHugh $B$, Murray D, Doran $P$, Buggy DJ. Effects of sevoflurane on breast cancer cell function in vitro. Anticancer Res. 2013;33:4255-60.

26. Bourguignon LY, Singleton PA, Zhu H, Zhou B. Hyaluronan promotes signaling interaction between CD44 and the transforming growth factor beta receptor I in metastatic breast tumor cells. J Biol Chem. 2002;277:39703-12.

27. Liang H, Yang CX, Zhang B, Wang HB, Liu HZ, Lai XH, et al. Sevoflurane suppresses hypoxia-induced growth and metastasis of lung cancer cells via inhibiting hypoxia-inducible factor-1alpha. J Anesth. 2015;29:821-30.

28. Linder S. The matrix corroded: podosomes and invadopodia in extracellular matrix degradation. Trends Cell Biol. 2007;17:107-17.

29. Chan KT, Cortesio CL, Huttenlocher A. FAK alters invadopodia and focal adhesion composition and dynamics to regulate breast cancer invasion. J Cell Biol. 2009;185:357-70.

30. Carragher NO, Frame MC. Focal adhesion and actin dynamics: a place where kinases and proteases meet to promote invasion. Trends Cell Biol. 2004;14:241-9.

31. Nam K, Oh S, Lee KM, Yoo SA, Shin I. CD44 regulates cell proliferation, migration, and invasion via modulation of c-Src transcription in human breast cancer cells. Cell Signal. 2015;27:1882-94.

32. Franken NA, Rodermond HM, Stap J, Haveman J, van Bree C. Clonogenic assay of cells in vitro. Nat Protoc. 2006;1:2315-9.

33. Bruce DL, Lin HS, Bruce WR. Reduction of colony-forming cell sensitivity to arabinosylcytosine by halothane anesthesia. Cancer Res. 1970;30:1803-5.

34. Ebert T, Schmid P III. Inhalation anesthesia. In:Barash PG, Cullen BF, Stoeltimh RK, editors. Clinical anesthesia. 4th ed. Philadelphia: Lippincott Williams \& Wilkins; 2001. p. 377-87.

35. Esper T, Wehner M, Meinecke CD, Rueffert H. Blood/Gas partition coefficients for isoflurane, sevoflurane, and desflurane in a clinically relevant patient population. Anesth Analg. 2015;120:45-50.

36. Honemann CW, Washington J, Honemann MC, Nietgen GW, Durieux ME. Partition coefficients of volatile anesthetics in aqueous electrolyte solutions at various temperatures. Anesthesiology. 1998;89:1032-5.

37. Wigmore TJ, Mohammed $\mathrm{K}$, Jhanji S. Long-term survival for patients undergoing volatile versus IV anesthesia for cancer surgery: a retrospective analysis. Anesthesiology. 2016;124:69-79.

38. Jiang $Y$, Gou H, Zhu J, Tian S, Yu L. Lidocaine inhibits the invasion and migration of TRPV6-expressing cancer cells by TRPV6 downregulation. Oncol Lett. 2016;12:1164-70.

39. Enlund M, Berglund A, Andreasson K, Cicek C, Enlund A, Bergkvist L. The choice of anaesthetic-sevoflurane or propofol-and outcome from cancer surgery: a retrospective analysis. Ups J Med Sci. 2014;119:251-61. 